\title{
Differences in discontinuation of statin treatment in women and men with advanced cancer disease
}

\author{
Helena Bergström ${ }^{1}$, Elsa Brånvall ${ }^{2,3}$, Maria Helde-Frankling ${ }^{1,2}$ and Linda Björkhem-Bergman ${ }^{1,2^{*}}$
}

\begin{abstract}
Background: Statins are often discontinued in patients with advanced cancer since the net effect of treatment is considered negative. However, guidelines concerning discontinuation of statin treatment are lacking. The aim of this study was to investigate any differences in time of discontinuation of statin treatment between men and women with advanced cancer disease.
\end{abstract}

Methods: Medical records from 195 deceased palliative cancer patients from a previous study cohort were reviewed. Patients treated with statins 2 years before death were identified as "statin users." The time of discontinuation of statin therapy was identified and correlated to time of death. Only patients that had incurable cancer disease at time of statin discontinuation were included in the analysis.

Results: Fifty-four patients were identified as statin users, 29 women and 25 men. The average time span between discontinuation of statin treatment and time of death was significantly longer in women than in men, 10 months compared to 4 months $(p<0.01$ ), with a range of 1-24 months among women and 1-12 months for men. All patients died due to their cancer disease. More men than women had a history of stroke or cardiac infarction $(p=0.02)$. There were no differences in age, socioeconomic factors, or survival time from study inclusion between men and women. There was no difference in self-assessed quality of life (QoL) between statin users who had discontinued statin treatment and those who are still on treatment. Men generally assessed their QoL lower than women in this study $(p=0.03)$.

Conclusion: Statin treatment was discontinued earlier in women than in men in patients with advanced cancer. The data suggest that statins may be discontinued earlier in men as well, since earlier discontinuation did not affect cardiovascular mortality.

Keywords: Statins, Palliative care, Gender, Vitamin D, Cholesterol

\section{Background}

In palliative care, the overall aims are prevention from and relief of suffering in patients with life-threatening illnesses, as well as improvement of quality of life. The goal is neither to prolong life nor to hasten death. Therefore, it is important that side effects of any medical treatment do not outweigh possible beneficial effects.

\footnotetext{
* Correspondence: linda.bjorkhem-bergman@ki.se

${ }^{1}$ Department of Neurobiology, Care Sciences and Society (NVS), Division of Clinical Geriatrics, Karolinska Institutet, Blickagången 16, Neo floor 7, SE-141 83 Huddinge, Sweden

${ }^{2}$ Palliative Home Care and Hospice Ward, ASIH Stockholm Södra, Bergtallsvägen

12, SE-125 59 Älvsjö, Sweden

Full list of author information is available at the end of the article
}

Statins (3-hydroxy-3-methylglutaryl-coenzyme A reductase inhibitors) are efficient in lowering cholesterol in the circulation, and large clinical trials have shown that statin treatment leads to prolonged survival in risk groups due to reduced cardiovascular disease burden [1]. However, since the preventive effects of statins on cardiovascular disease require long-term treatment, beneficial effects of statins are not to be expected in terminally ill cancer patients. Statin treatment is therefore often discontinued in patients with advanced cancer disease. However, there are no clear guidelines for statin discontinuation in palliative cancer patients. Since guidelines are lacking, the decision regarding discontinuation often depends on how the individual physician values risk and benefit, as well as on local

(c) The Author(s). 2018 Open Access This article is distributed under the terms of the Creative Commons Attribution 4.0 International License (http://creativecommons.org/licenses/by/4.0/), which permits unrestricted use, distribution, and 
practices. Interestingly, during recent years, several epidemiological studies have suggested a possible cancer-preventive effect of statin treatment, as well as a reduced cancer-related mortality [2-7].

Statins are generally considered to be well-tolerated drugs. However, during recent years, several reports have demonstrated that statin-induced muscular side effects, such as myalgia, are more common than first predicted in clinical trials [8]. In fact, $10-15 \%$ of patients prescribed with statins may experience adverse muscle symptoms $[9,10]$, and the risk of myalgia is more common in women than in men [11]. One study carried out in cancer patients showed that in patients $>80$ years of age, statin use was associated with a significant increase in self-reported pain [12].

Low vitamin D levels (25-hydroxyvitamin D) have been linked to increased risk of statin-induced myopathy in several observational studies [13-15]. In a Swedish study, we could demonstrate that 25-hydroxyvitamin D levels $<50 \mathrm{nmol} / \mathrm{L}$ were associated with a fourfold increase in risk of statin-induced myopathy [14]. In addition, we and others have shown that palliative cancer patients generally have low 25-hydroxyvitamin D levels [16-20]. Thus, palliative cancer patients have an increased risk of statin-induced myopathy.

The aim of this study was to investigate whether there was a difference in time of statin discontinuation before time of death between women and men admitted to a palliative home care unit in Sweden. We also reviewed the literature regarding discontinuation of statins in terminally ill cancer patients.

\section{Methods}

\section{Study cohort}

We collected data from 195 deceased cancer patients who had participated in two studies on vitamin D status at our Palliative Care Unit in Stockholm, Sweden (ASIH Stockholm Södra), between 2014 and 2016. This Palliative Care Unit includes both advanced medical home care, i.e., patients receiving medical care in their own homes, and a hospice ward for in-patients. Results from these studies have been published elsewhere $[16,19]$. Both studies included patients suffering from advanced, incurable cancer disease, who were admitted to our palliative unit, had a lifetime expectancy of more than 1 month, and who were able to assess quality of life (QoL) with the Edmonton Symptom Assessment System (ESAS) [21]. ESAS is a scale from 0 to 10 where 0 is the best QoL and 10 is the worst QoL.

The first study, carried out in 2014-2015, was an observational study where 25 -hydroxyvitamin $\mathrm{D}$ was measured and related to opioid dose, infectious burden, and QoL [16]. In the second study, carried out in 2015-2016, the same parameters were studied in a cohort where patients with 25-hydroxyvitamin $\mathrm{D}<75 \mathrm{nmol} / \mathrm{L}$ were offered treatment with vitamin D $4000 \mathrm{IE} /$ day for 3 months [19]. Patients from both of these studies were merged into one combined cohort in which we have data on age, sex, cancer disease, survival time from inclusion, QoL, opioid dose, antibiotic consumption the month before and after inclusion, and levels of albumin, $C$ reactive protein (CRP), and 25-hydroxyvitamin $\mathrm{D}$ at time of inclusion. The patients were recruited consecutively and could have any type of cancer.

From this combined cohort, we identified all 195 patients who are now deceased. Due to of the joint medical records in Stockholm County health care system, all prescribed drugs during the last 10 years can be identified. In the cohort of 195 patients, we identified 55 patients who had been prescribed statin treatment for more than 1 month during the last 10 years. However, one patient had discontinued statin use before being diagnosed with cancer and was not included in the analysis. Fifty-four patients discontinued statin treatment at some point in time after being diagnosed with incurable cancer disease and were included in the analysis. The earliest discontinuation of statin treatment in relation to death was 24 months before death.

\section{Data extraction}

Data from medical records were collected regarding statin type and dose, indication for statin treatment (primary or secondary prevention), cardiovascular morbidity, time for discontinuation of statin treatment, reason for statin discontinuation if stated, responsible physician, time of death, and the major cause of death according to the death certificate. In addition, we collected data on place of residence and level of education/profession if stated in the medical record. Data regarding age, sex, cancer diagnosis, QoL, and levels of 25-hydroxyvitamin D, CRP, and albumin had been extracted previously.

\section{Statistical analysis}

Statistical analyses were performed using Graph Pad Prism vs 6.0. Comparisons of termination of statin treatment in relation to death; age; levels of CRP, albumin, and 25-hydroxyvitamin D; survival time; and QoL were performed using Student's $t$ test. The data showed Gaussian distribution. Comparisons of proportions of women and men treated with statins due to secondary or primary prevention were performed using Fisher's exact test.

\section{Ethics statement}

The original studies were approved by the local Ethical Committee at Karolinska Institutet, Stockholm, Sweden (Dnr: 2014/455-31/4 and 2015/776-31), and were performed in accordance with the Declaration of Helsinki. Written informed consent was obtained from all patients 
before inclusion in the original studies, including permission of review of medical records.

\section{Results}

\section{Study group of statin users}

Out of the 54 statin users, there were 29 women and 25 men. Baseline characteristics, including age, laboratory data, type of statin, indication for statin use, and presence of previous cardiovascular event are presented in Table 1. Distribution of types of cancers is presented in Table 2. There were no differences in age and levels of albumin, CRP, or 25-hydroxyvitamin $\mathrm{D}$ between the men and women (Table 1). Simvastatin was the most common statin used in both men and women and is still the most frequently used statin in Sweden. At time of inclusion in the original vitamin D studies, only three women $(10 \%)$ and seven men $(28 \%)$ were still on statin treatment. One
Table 2 Types of cancers in the 54 statin users in the study cohort. Values show number of patients

\begin{tabular}{llll}
\hline Type of cancer & All $(N=54)$ & Men $(N=25)$ & Women $(N=29)$ \\
\hline Lung & 13 & 6 & 7 \\
Breast & 5 & 1 & 4 \\
Gastrointestinal & 12 & 7 & 5 \\
Pancreas, liver & 7 & 1 & 6 \\
Sarcoma & 1 & 0 & 1 \\
Urothelial & 5 & 5 & 0 \\
Hematological & 3 & 3 & 0 \\
Brain tumor & 2 & 2 & 0 \\
Gynecological & 3 & 0 & 3 \\
Melanoma & 1 & 1 & 0 \\
Ear-nose and throat & 2 & 0 & 2 \\
\hline
\end{tabular}

Table 1 Demographic data of the 54 statin users in the study cohort. Age, lab values, and survival time is at time of inclusion in the original studies $[16,19]$. All values are presented as mean \pm SD if not specified otherwise. $P$ values show statistically significant differences between women and men. Survival time is from time of inclusion in the original vitamin $\mathrm{D}$ study

\begin{tabular}{|c|c|c|c|c|}
\hline & Total $(N=54)$ & Men $(N=25)$ & Women $(N=29)$ & $p$ \\
\hline \multicolumn{5}{|l|}{ Patients' characteristics } \\
\hline Age (years) & $72 \pm 10$ & $71 \pm 11$ & $73 \pm 8$ & ns \\
\hline Age > 75 years, $n(\%)$ & 20 & 10 & 10 & ns \\
\hline Albumin $(g / L)$ & $27 \pm 7$ & $27 \pm 6$ & $27 \pm 7$ & ns \\
\hline CRP (mg/L) & $65 \pm 27$ & $63 \pm 126$ & $66 \pm 82$ & ns \\
\hline 25-OHD (nmol/L) & $45 \pm 29$ & $43 \pm 26$ & $47 \pm 32$ & ns \\
\hline ESAS QoL & $5.7 \pm 2.5$ & $6.5 \pm 2.4$ & $5.0 \pm 2.4$ & 0.03 \\
\hline History of stroke, $n$ & 6 & 4 & 2 & ns \\
\hline History of myocardial infarction, $n$ & 12 & 8 & 4 & ns \\
\hline Survival time (months) & $3.3 \pm 4.5$ & $2.2 \pm 2.5$ & $4.3 \pm 5.5$ & $\begin{array}{l}\text { ns } \\
(0.10)\end{array}$ \\
\hline \multicolumn{5}{|l|}{ Highest educational level } \\
\hline University degree & 4 & 2 & 2 & ns \\
\hline No university degree & 30 & 14 & 16 & ns \\
\hline Unknown & 20 & 9 & 11 & ns \\
\hline \multicolumn{5}{|l|}{ Indication for statin use } \\
\hline Primary prevention, $n$ & 36 & 13 & 23 & \\
\hline Secondary prevention, $n$ & 18 & 12 & 6 & 0.03 \\
\hline \multicolumn{5}{|l|}{$\begin{array}{l}\text { Type of statin, } n \\
\text { mean dose (mg) }\end{array}$} \\
\hline Simvastatin & $\begin{array}{l}41 \\
28 \mathrm{mg}\end{array}$ & $\begin{array}{l}21 \\
31 \mathrm{mg}\end{array}$ & $\begin{array}{l}20 \\
24 \mathrm{mg}\end{array}$ & ns \\
\hline Atorvastatin & $\begin{array}{l}10 \\
23 \mathrm{mg}\end{array}$ & $\begin{array}{l}3 \\
27 \mathrm{mg}\end{array}$ & $\begin{array}{l}7 \\
19 \mathrm{mg}\end{array}$ & ns \\
\hline Rosuvastatin & $\begin{array}{l}2 \\
10 \mathrm{mg}\end{array}$ & 0 & $\begin{array}{l}2 \\
10 \mathrm{mg}\end{array}$ & ns \\
\hline Pravastatin & $\begin{array}{l}1 \\
20 \mathrm{mg}\end{array}$ & $\begin{array}{l}1 \\
20 \mathrm{mg}\end{array}$ & 0 & ns \\
\hline
\end{tabular}


woman and four men were after inclusion in the study supplemented with vitamin D 4000 IE/day for up to 3 months.

All patients were living in the southern part of Stockholm in low- to middle-income areas. There was no difference between men and women in place of residence. The educational level was also similar between men and women. Only $7 \%(n=2)$ of the men and $7 \%(n=2)$ of the women had a university degree.

There was no statistically significant difference in survival time between women and men after inclusion in the vitamin D studies (Table 1).

\section{Statin discontinuation}

The average time from statin discontinuation to death was significantly longer in women than in men; average $10 \pm 9.4$ months compared to $4 \pm 3.5$ months $(p<0.01)$
(Fig. 1a). As shown in Fig. 1b, half of the women had their statin discontinued 24-18 months before death, while no men had their statin discontinued earlier than 12 months before death. Indication for statin treatment was secondary prevention after a cardiovascular event in 6 out of 29 women (21\%) and in 12 out of 25 men (48\%) (Fig. 2), a difference that was statistically significant (Fisher's exact test $p=0.03$ ).

It should be noted that 13 men and 23 women received statins as primary prevention, although they were suffering from a life-limiting disease (Table 1). There was no trend towards earlier discontinuation of statin treatment where the indication was primary prevention. In fact, seven of the nine men and seven of the eight women who continued their statin treatment until 1 month before death were prescribed statins as primary prevention.

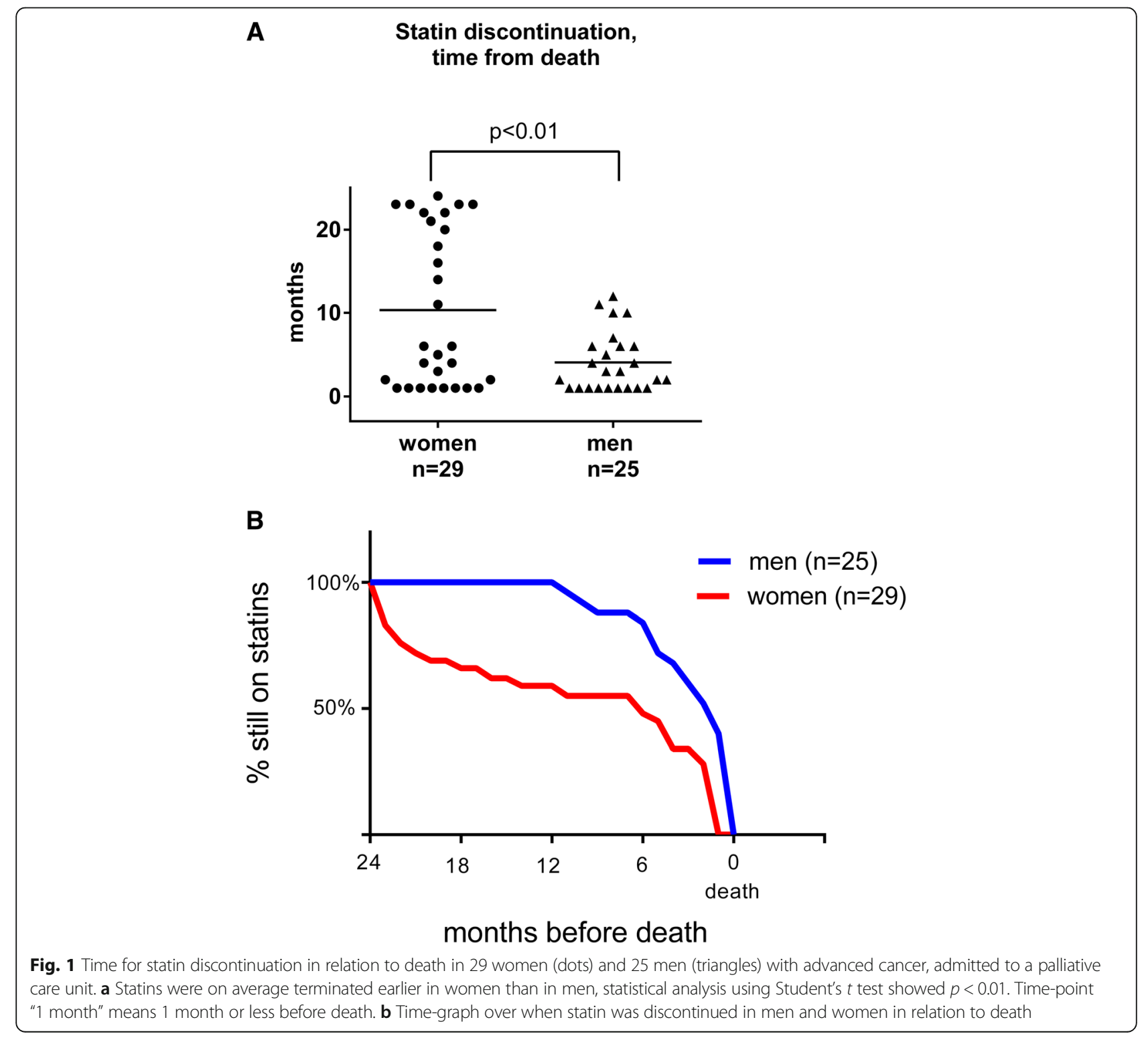




\section{Indication for statin use}
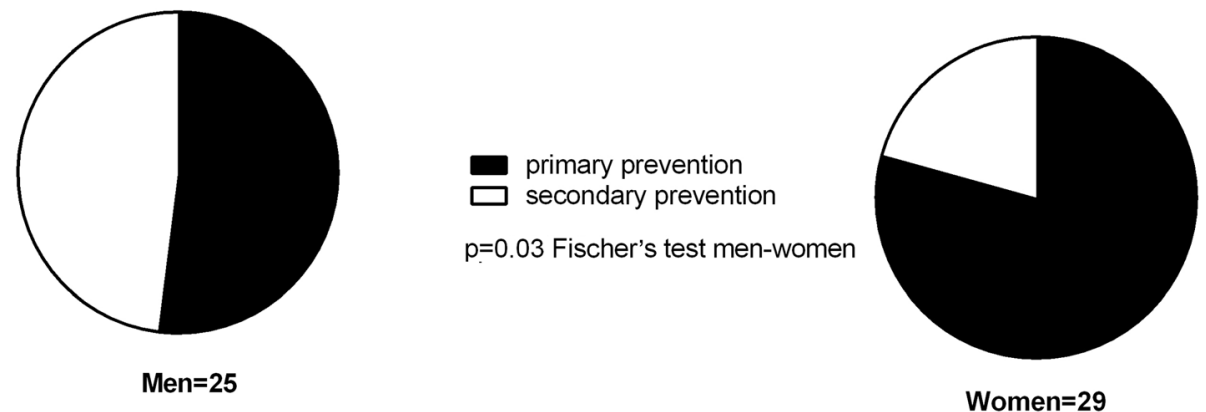

Fig. 2 Indication for statin treatment in 29 women and 25 men with advanced cancer admitted to a palliative care unit. The indication for statin treatment was secondary prevention after a cardiovascular event in 6 of 29 women (21\%) and in 12 of 25 men (48\%), a difference that was statistically significant $(p=0.03)$

At time of study inclusion, $10 \%$ of the women and $28 \%$ of the men were still on statin treatment. There was no difference in self-assessed QoL in the patients with ongoing statin treatment and those who had terminated statin treatment (Fig. 3a). However, men generally assessed their quality of life lower than women, with ESAS differing 1.5 points between the groups ( $p=0.03$ ) (Fig. 3b). In 48 of the 54 cases, a physician at the Palliative Unit had discontinued statin treatment. In six cases, a physician at the hospital (oncologists and geriatricians) had terminated the treatment. In summary, statin was discontinued by 29 different physicians among the 54 patients.

\section{Reasons for statin discontinuation}

Medical records did not state statin-induced myopathy or other adverse reactions as the cause of statin discontinuation in any of the patients. In 16 women and 12 men, there was no notification in the medical record about reason for statin discontinuation. In 26 patients, there was some notion in the patients' medical records as to why statin use was discontinued (Table 3).

The most common causes in both men and women were "risk for harm greater than benefit" (20\%) or "short life-time expectancy" (19\%).

\section{Cause of death}

All patients died due to their cancer disease according to the death certificate, and no one died due to cardiovascular events.

\section{Discussion}

In this study, statin treatment was generally terminated earlier in women with advanced cancer as compared to men. This difference was not explained by age, sociodemographic factors, cancer type, or expected survival time. One possible reason for continued statin treatment in men could be a difference in indication for statin use, since secondary prevention was more common in men. Physicians are likely to be more prone to continue statin treatment in a patient with an earlier cardiovascular event where the risk reduction with statin is expected to be more pronounced. However, the majority of both men and women who were on statin treatment until the last month of life had statin treatment as the primary prevention, indicating that previous cardiovascular events were not part of the assessment when statins should be discontinued. This is in line with the findings in an earlier retrospective study $(n=539)$ in poor-prognosis cancer patients showing that statin treatment was continued despite life-limiting disease even when the indication was primary prevention [22].

Half of the women had their statin discontinued 24-18 months before death, while no men had their statin discontinued earlier than 12 months before death. It could be hypothesized that the life expectancy was overestimated in the male patients or underestimated in the women. Another possible explanation is that men had their cancers evaluated as incurable at a later stage than the women did in the cohort.

Interestingly, men generally assessed their QoL lower than women, and there was no difference in self-assessed QoL between former and current statin users, i.e., statin use was not associated with increased QoL. No patient died from a cardiovascular event. Thus, there was no apparent benefit for the men in this study to continue with statin treatment.

To our knowledge, no previous study has been carried out to study gender differences in statin discontinuation in patients with advanced cancer disease. In studies on statin discontinuation in non-cancer patients, the majority of the participants have been men [23].

In a study by Kutner and co-workers, 381 statin users with life-threatening illness were randomized to 


\section{A QoL at inclusion in the vitamin D study}

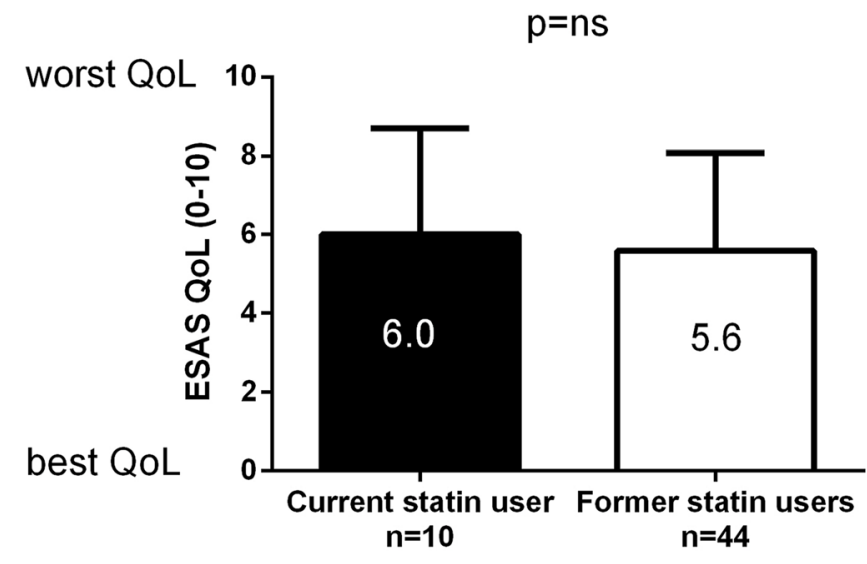

B

$\mathrm{p}=0.03$

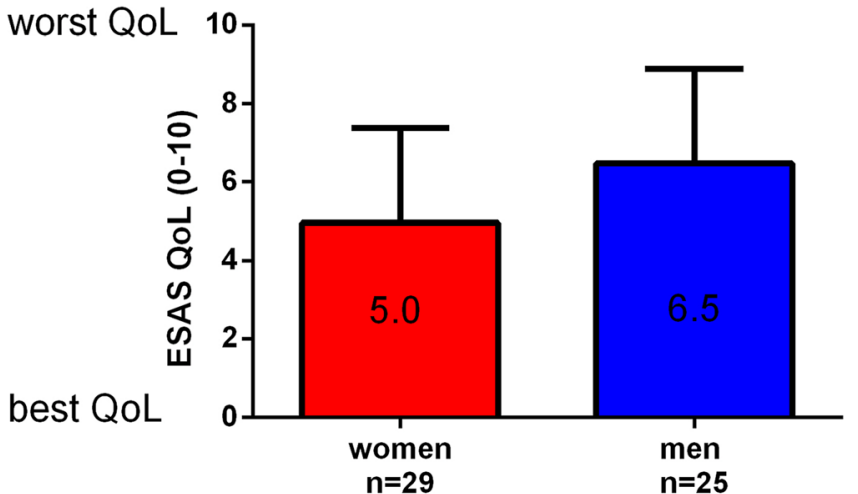

Fig. 3 Average assessed quality of life $(\mathrm{Q} L \mathrm{~L})$ in a current $(n=10)$ and former $(n=44)$ statin users with advanced cancer admitted to Palliative Care. $\mathbf{b}$ Men (current and former statin users $n=25$ ) generally assessed their QoL at inclusion in the study worse than women (current and former statin users $n=29$ ), Student's $t$ test $p=0.03$. QoL was measured using the Edmonton Symptom Assessment System (ESAS), a scale from 0 to 10 where 0 is the best QoL and 10 is the worst QoL

Table 3 Causes of statin termination as stated in the medical records of the 54 statin users in the study cohort. Values show number of patients and \% within parenthesis

\begin{tabular}{llll}
\hline $\begin{array}{l}\text { Reasons for termination } \\
\text { of statin treatment }\end{array}$ & $\begin{array}{l}\text { Total } \\
(n=54) \\
n(\%)\end{array}$ & $\begin{array}{l}\text { Men } \\
(n=25) \\
n(\%)\end{array}$ & $\begin{array}{l}\text { Women } \\
n=29) \\
n(\%)\end{array}$ \\
\hline Risk for harm greater than benefit & $11(20)$ & $8(32)$ & $3(10)$ \\
Short lifetime expectancy & $10(19)$ & $4(16)$ & $6(21)$ \\
Cachexia & $3(6)$ & $1(4)$ & $2(7)$ \\
Fatigue & $1(2)$ & $0(0)$ & $1(3)$ \\
Dysphagia & $1(2)$ & $0(0)$ & $1(3)$ \\
Not specified & $28(52)$ & $12(48)$ & $16(55)$ \\
\hline
\end{tabular}

discontinue statins $(n=189)$ or to continue statin use $(n=192)$. In this study, statin discontinuation resulted in increased QoL and did not affect survival time [24]. The same research team also carried out a study on patient perceptions of discontinuation of statin therapy $(n=297)$ [25]. This study showed that patients with life-threatening illnesses were mostly positive to discontinue statin-treatment, including spending less money on medications and having a better quality of life. Fewer than $5 \%$ of the participants expressed concerns about the discontinuation, including feelings of being abandoned by their physician [25].

There are well-established differences between the sexes in the prevalence of risk factors for cardiovascular disease, such as hypertension, hypercholesterolemia, and diabetes. Also, women are more likely to be older and have more co-morbidities than men at the time of onset 
of cardiovascular disease [26]. In addition, there are sex differences in sociodemographic factors such as educational level and disposable income, and it has been shown that such factors influence the likelihood of continuing statin treatment or not [27]. However, in the current cohort, there were no significant sociodemographic differences between men and women when measured as educational level and place of residence.

The patterns of statin treatment differ between the sexes, as women are less likely to be both prescribed [28] and dispensed statins for secondary prevention [29]. In addition, women report a higher frequency of adverse drug reactions in general as compared to men [30]. In a prospective observational study of statin-induced myopathy in an outpatient setting, women reported a higher frequency of myopathy and other adverse drug reactions, as well as a more negative impact of daily life activities [11]. Combined, these factors may contribute to a lower likelihood of adequate treatment with statins for women and may also contribute to a higher propensity for statin discontinuation among women in our cohort.

It has been suggested in epidemiological studies that statin use may be associated with prolonged survival in several cancer types, including prostate, colorectal, endometrial, liver cancer, and myeloma [2-7]. In vitro and animal experiments have also shown that statins may inhibit progression of cancer cells [31-33]. However, population-based observational studies may be associated with methodological biases and there are so far no large, interventional studies showing prolonged survival in cancer patients taking statins, nor any general recommendations to continue statin treatment for cancer-preventive effects. Also importantly, such an inhibiting effect on cancer progression is hypothesized to be long-term and thus not likely to be of any major importance in a late palliative setting.

A disadvantage of continued statin therapy, besides the general risk of myopathy $[9,10]$ and increased pain [12], is the risk of drug-drug interactions. All lipid-soluble statins, e.g., simvastatin and atorvastatin, are metabolized by hepatic cytochrome P450 (CYP) enzymes, while the water-soluble pravastatin is mainly eliminated in the urine. In cancer patients with concomitant drugs that inhibit CYP3A4, e.g., fluconazole, there is a risk of drug-drug interactions with increased concentrations of lipid-soluble statins and subsequently increased risk of adverse events and myotoxicity $[34,35]$.

There are several limitations to this study. First, the sample size is small and the data was collected at one single center. Thus, the findings presented here need to be confirmed in a larger and preferably multicenter study. Second, we have incomplete data on socioeconomic factors in men and women that might affect when statins are discontinued, and the patients' opinions regarding statin discontinuation are not assessed. Furthermore, data on the history of smoking, diabetes, and other co-morbidities are lacking.

Despite the limitations, this is to our knowledge the first study in which sex differences in statin discontinuation is studied in patients with advanced cancer disease and the results from this pilot-study could be used for power calculation to optimize the design of a future study,.

\section{Conclusion}

Statin treatment in patients with advanced cancer was discontinued earlier in women than in men. Discontinuation of statins did not affect cardiovascular mortality and did not decrease QoL suggesting that statins may be safely terminated earlier in men as well. However, these findings need to be confirmed in a larger study that is now in the planning phase at our Palliative Unit at ASIH Stockholm Södra.

\section{Abbreviations \\ 25-OHD: 25-Hydroxyvitamin D; CRP: C reactive protein; ESAS: Edmonton Symptom Assessment System; ns: Non-significant; QoL: Quality of life}

\section{Acknowledgements}

We are most grateful to all patients that have participated in the original studies.

\section{Funding}

Financial support was provided through Stockholm County Council (ALF20160036), The Swedish Cancer Society (CAN 2015/249 and CAN 2017/ 233), ASIH Stockholm Södra, and Karolinska Institutet.

Availability of data and materials

The dataset is available from the corresponding author on reasonable request.

\section{Authors' contributions}

$H B$ and $L B B$ designed the study. MHF and LBB performed the original clinical study. $H B, E B, M H F$, and $L B B$ collected the new data for this study and analyzed the data. $\mathrm{HB}$ and LBB wrote the first draft of the manuscript. All authors

contributed to the final version of the manuscript and have read and approved the final version of this manuscript.

Ethics approval and consent to participate

The study was approved by the local Ethical Committee at Karolinska Institutet (Dnr: 2014/455-31/4 and 2015/776-31) and was performed in accordance with the Declaration of Helsinki. Written informed consent was obtained from all study participants before inclusion.

Consent for publication

Not applicable.

\section{Competing interests}

The authors declare that they have no competing interests.

\section{Publisher's Note}

Springer Nature remains neutral with regard to jurisdictional claims in published maps and institutional affiliations.

\section{Author details}

'Department of Neurobiology, Care Sciences and Society (NVS), Division of Clinical Geriatrics, Karolinska Institutet, Blickagången 16, Neo floor 7, SE-141 83 Huddinge, Sweden. ${ }^{2}$ Palliative Home Care and Hospice Ward, ASIH Stockholm Södra, Bergtallsvägen 12, SE-125 59 Älvsjö, Sweden. ${ }^{3}$ Division of Clinical Epidemiology, Department of Medicine Solna, Karolinska Institutet, SE-171 77 Stockholm, Sweden. 
Received: 27 August 2018 Accepted: 11 October 2018

Published online: 20 October 2018

\section{References}

1. Cholesterol Treatment Trialists C, Baigent C, Blackwell L, Emberson J, Holland LE, Reith C, et al. Efficacy and safety of more intensive lowering of LDL cholesterol: a meta-analysis of data from 170,000 participants in 26 randomised trials. Lancet. 2010;376(9753):1670-81.

2. Björkhem-Bergman L, Backheden M, Söderberg Lofdal K. Statin treatment reduces the risk of hepatocellular carcinoma but not colon cancer-results from a nationwide case-control study in Sweden. Pharmacoepidemiol Drug Saf. 2014;23(10):1101-6

3. Dobrzycka M, Spychalski P, Lachinski AJ, Kobiela P, Jedrusik P, Kobiela J. Statins and colorectal cancer - a systematic review. Exp Clin Endocrinol Diabetes. 2018. https://doi.org/10.1055/a-0668-5692.

4. Sperling DC, Verdoodt F, Kjaer Hansen M, Dehlendorff C, Friis S, Kjaer SK. Statin use and mortality among endometrial cancer patients: a Danish nationwide cohort study. Int J Cancer. 2018. https://doi.org/10.1002/ijc. 31625.

5. Nielsen SF, Nordestgaard BG, Bojesen SE. Statin use and reduced cancerrelated mortality. N Engl J Med. 2012;367(19):1792-802.

6. Sanfilippo KM, Keller J, Gage BF, Luo S, Wang TF, Moskowitz G, et al. Statins are associated with reduced mortality in multiple myeloma. J Clin Oncol. 2016:34(33):4008-14

7. Yu O, Eberg M, Benayoun S, Aprikian A, Batist G, Suissa S, et al. Use of statins and the risk of death in patients with prostate cancer. J Clin Oncol. 2014;32(1):5-11.

8. Fernandez G, Spatz ES, Jablecki C, Phillips PS. Statin myopathy: a common dilemma not reflected in clinical trials. Cleve Clin J Med. 2011;78(6):393-403.

9. Joy TR, Hegele RA. Narrative review: statin-related myopathy. Ann Intern Med. 2009:150(12):858-68.

10. Magni P, Macchi C, Morlotti B, Sirtori CR, Ruscica M. Risk identification and possible countermeasures for muscle adverse effects during statin therapy. Eur J Intern Med. 2015;26(2):82-8.

11. Skilving I, Eriksson M, Rane A, Ovesjö ML. Statin-induced myopathy in a usual care setting-a prospective observational study of gender differences. Eur J Clin Pharmacol. 2016:72(10):1171-6.

12. Turner JP, Shakib S, Singhal N, Hogan-Doran J, Prowse R, Johns S, et al. Statin use and pain in older people with cancer: a cross-sectional study. J Am Geriatr Soc. 2014;62(10):1900-5.

13. Mergenhagen K, Ott M, Heckman K, Rubin LM, Kellick K. Low vitamin D as a risk factor for the development of myalgia in patients taking high-dose simvastatin: a retrospective review. Clin Ther. 2014;36(5):770-7.

14. Ovesjö ML, Skilving I, Bergman P, Rane A, Ekström L, Björkhem-Bergman L. Low vitamin $D$ levels and genetic polymorphism in the vitamin $D$ receptor are associated with increased risk of statin-induced myopathy. Basic Clin Pharmacol Toxicol. 2016;118(3):214-8.

15. Palamaner Subash Shantha G, Ramos J, Thomas-Hemak L, Pancholy SB. Association of vitamin D and incident statin induced myalgia--a retrospective cohort study. PLoS One. 2014;9(2):e88877.

16. Bergman P, Sperneder S, Höijer J, Bergqvist J, Björkhem-Bergman L. Low vitamin d levels are associated with higher opioid dose in palliative cancer patients - results from an observational study in Sweden. PLoS One. 2015; 10(5):e0128223.

17. Björkhem-Bergman $L$, Bergman $P$. Vitamin $D$ and patients with palliative cancer. BMJ Support Palliat Care. 2016;6(3):287-91.

18. Der T, Bailey BA, Youssef D, Manning T, Grant WB, Peiris AN. Vitamin D and prostate cancer survival in veterans. Mil Med. 2014;179(1):81-4.

19. Helde-Frankling M, Höijer J, Bergqvist J, Björkhem-Bergman L. Vitamin D supplementation to palliative cancer patients shows positive effects on pain and infections-results from a matched case-control study. PLoS One. 2017; 12(8):e0184208.

20. Shi L, Nechuta S, Gao YT, Zheng Y, Dorjgochoo T, Wu J, et al. Correlates of 25-hydroxyvitamin D among Chinese breast cancer patients. PLoS One. 2014;9(1):e86467

21. Watanabe SM, Nekolaichuk $\mathrm{CL}$, Beaumont C. The Edmonton Symptom Assessment System, a proposed tool for distress screening in cancer patients: development and refinement. Psycho-Oncology. 2012;21(9):977-85.

22. Bayliss EA, Bronsert MR, Reifler LM, Ellis JL, Steiner JF, McQuillen DB, et al. Statin prescribing patterns in a cohort of cancer patients with poor prognosis. J Palliat Med. 2013;16(4):412-8.
23. Narayan SW, Nishtala PS. Discontinuation of preventive medicines in older people with limited life expectancy: a systematic review. Drugs Aging. 2017; 34(10):767-76

24. Kutner JS, Blatchford PJ, Taylor DH Jr, Ritchie CS, Bull JH, Fairclough DL, et al. Safety and benefit of discontinuing statin therapy in the setting of advanced, life-limiting illness: a randomized clinical trial. JAMA Intern Med. 2015:175(5):691-700.

25. Tjia J, Kutner JS, Ritchie CS, Blatchford PJ, Bennett Kendrick RE, Prince-Paul $\mathrm{M}$, et al. Perceptions of statin discontinuation among patients with lifelimiting illness. J Palliat Med. 2017;20(10):1098-103.

26. Garcia M, Mulvagh SL, Merz CN, Buring JE, Manson JE. Cardiovascular disease in women: clinical perspectives. Circ Res. 2016;118(8):1273-93.

27. Ofori-Asenso R, Jakhu A, Curtis AJ, Zomer E, Gambhir M, Jaana Korhonen M, et al. A systematic review and meta-analysis of the factors associated with nonadherence and discontinuation of statins among people aged $>/=65$ years. J Gerontol A Biol Sci Med Sci. 2018;73(6):798-805.

28. Sjölander $M$, Eriksson M, Glader EL. Social stratification in the dissemination of statins after stroke in Sweden. Eur J Clin Pharmacol. 2013;69(5):1173-80.

29. Geary L, Aronius J, Wettermark B, Hasselstrom J, Sjoborg B, von Euler M. Sociodemographic factors are associated with utilisation of statins after ischaemic stroke/TIA. Int J Clin Pract. 2017;71(3-4). https://doi.org/10.1111/ ijcp.12936.

30. Lazarou J, Pomeranz BH, Corey PN. Incidence of adverse drug reactions in hospitalized patients: a meta-analysis of prospective studies. JAMA. 1998; 279(15):1200-5.

31. Björkhem-Bergman L, Acimovic J, Torndal UB, Parini P, Eriksson LC. Lovastatin prevents carcinogenesis in a rat model for liver cancer. Effects of ubiquinone supplementation. Anticancer Res. 2010;30(4):1105-12.

32. Skogastierna $C$, Johansson $M$, Parini P, Eriksson M, Eriksson LC, Ekstrom $L$, et al. Statins inhibit expression of thioredoxin reductase 1 in rat and human liver and reduce tumour development. Biochem Biophys Res Commun. 2012;417(3):1046-51.

33. Spampanato C, De Maria S, Sarnataro M, Giordano E, Zanfardino M, Baiano $\mathrm{S}$, et al. Simvastatin inhibits cancer cell growth by inducing apoptosis correlated to activation of Bax and down-regulation of $\mathrm{BCL}-2$ gene expression. Int J Oncol. 2012:40(4):935-41.

34. Logue JM, Kiani B, Bitting RL. Pazopanib and statin-induced rhabdomyolysis. Case Rep Oncol. 2017;10(3):954-7.

35. Shaukat A, Benekli M, Vladutiu GD, Slack JL, Wetzler M, Baer MR. Simvastatinfluconazole causing rhabdomyolysis. Ann Pharmacother. 2003;37(7-8):1032-5.

\section{Ready to submit your research? Choose BMC and benefit from:}

- fast, convenient online submission

- thorough peer review by experienced researchers in your field

- rapid publication on acceptance

- support for research data, including large and complex data types

- gold Open Access which fosters wider collaboration and increased citations

- maximum visibility for your research: over $100 \mathrm{M}$ website views per year

At $\mathrm{BMC}$, research is always in progress.

Learn more biomedcentral.com/submission 